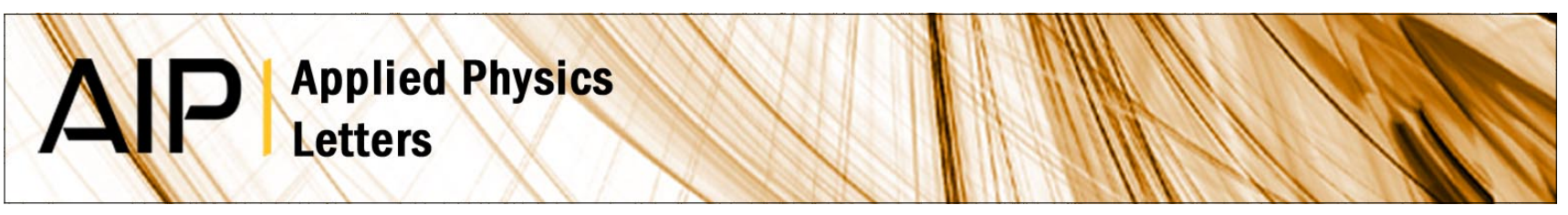

\title{
Boron-oxygen defect in Czochralski-silicon co-doped with gallium and boron
}

M. Forster, E. Fourmond, F. E. Rougieux, A. Cuevas, R. Gotoh et al.

Citation: Appl. Phys. Lett. 100, 042110 (2012); doi: 10.1063/1.3680205

View online: http://dx.doi.org/10.1063/1.3680205

View Table of Contents: http://apl.aip.org/resource/1/APPLAB/v100/i4

Published by the American Institute of Physics.

\section{Related Articles}

Inelastic carrier lifetime in bilayer graphene

Appl. Phys. Lett. 100, 032106 (2012)

Carrier dynamics in bulk GaN

J. Appl. Phys. 111, 023702 (2012)

Photon recycling effect on electroluminescent refrigeration

J. Appl. Phys. 111, 014511 (2012)

Characterization of deep levels in n-type and semi-insulating $4 \mathrm{H}-\mathrm{SiC}$ epitaxial layers by thermally stimulated current spectroscopy

J. Appl. Phys. 111, 014910 (2012)

Monte Carlo analysis of electron relaxation process and transport property of wurtzite $\ln N$

J. Appl. Phys. 111, 013711 (2012)

\section{Additional information on Appl. Phys. Lett.}

Journal Homepage: http://apl.aip.org/

Journal Information: http://apl.aip.org/about/about_the_journal

Top downloads: http://apl.aip.org/features/most_downloaded

Information for Authors: http://apl.aip.org/authors

\section{ADVERTISEMENT}

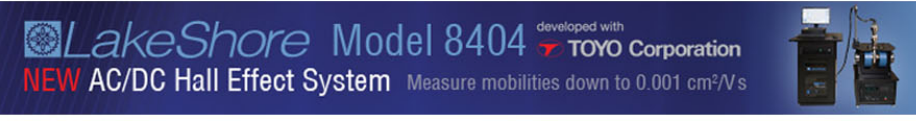




\title{
Boron-oxygen defect in Czochralski-silicon co-doped with gallium and boron
}

\author{
M. Forster, ${ }^{1,2,3, a)}$ E. Fourmond, ${ }^{2}$ F. E. Rougieux, ${ }^{3}$ A. Cuevas, ${ }^{3}$ R. Gotoh, ${ }^{4}$ K. Fujiwara,${ }^{4}$ \\ S. Uda, ${ }^{4}$ and M. Lemiti ${ }^{2}$ \\ ${ }_{1}^{1}$ APOLLON SOLAR, 66 cours Charlemagne, 69002 Lyon, France \\ ${ }^{2}$ INSA de LYON, INL, 7 av. J. Capelle, 69621 Villeurbanne Cedex, France \\ ${ }^{3}$ School of Engineering, College of Engineering and Computer Science, The Australian National University, \\ Canberra ACT 0200, Australia \\ ${ }^{4}$ Institute for Material Research, Tohoku University, 2-1-1 Katahira, Aoba-ku, Sendai 980-8577, Japan
}

(Received 20 November 2011; accepted 10 January 2012; published online 27 January 2012)

\begin{abstract}
We study the boron-oxygen defect in $\mathrm{Si}$ co-doped with gallium and boron with the hole density 10 times higher than the boron concentration. Instead of the linear dependence of the defect density on the hole density observed in boron and phosphorus compensated silicon, we find a proportionality to the boron concentration. This indicates the participation of substitutional, rather than interstitial, boron in the defect complex. The measured defect formation rate constant is proportional to the hole density squared, which gives credit to latent defect models against defect reactions limited by the diffusion and trapping of oxygen dimers by boron atoms. (C) 2012 American Institute of Physics. [doi:10.1063/1.3680205]
\end{abstract}

A degradation of the minority-carrier lifetime is known to occur in boron (B)-doped and oxygen (O)-containing crystalline silicon $(\mathrm{Si})$ under illumination or carrier injection. Therefore, solar cells made of B-doped Czochralski $(\mathrm{Cz})-\mathrm{Si}$ or cast multi-crystalline (mc)-Si suffer from a loss of conversion efficiency of up to $10 \%$ relative. This issue has to be addressed with particular care in the case of $\mathrm{Cz}-\mathrm{Si}$ containing high $\mathrm{O}$ concentrations or low-cost upgraded-metallurgical grade (Ref. 1) (UMG)-Si which usually contains larger B concentrations than standard Siemens purified Si. Since 2004 (Ref. 2) and until very recently, the observed degradation was believed to be due to the formation of a complex made up of one substitutional B atom $\left(\mathrm{B}_{\mathrm{s}}\right)$ and one interstitial $\mathrm{O}$ dimer $\left(\mathrm{O}_{2 \mathrm{i}}\right)$. This defect model was proposed after the observation that the saturated (i.e., after complete degradation) effective defect density $N_{\mathrm{t}, \mathrm{sat}} *$ exhibits a linear dependence on $\mathrm{B}_{\mathrm{s}}$ concentration $[\mathrm{B}]$ and a quadratic dependence on interstitial $\mathrm{O}$ concentration $\left[\mathrm{O}_{\mathrm{i}}\right]$. However, recent measurements made on $\mathrm{B}$ and phosphorus $(\mathrm{P})$ co-doped $p$-type Si (Refs. 3 and 4) showed that $N_{\mathrm{t} \text { sat }}$ * was proportional to the hole density $p_{0}$ (i.e., to the net dopant density $N_{\mathrm{A}}-N_{\mathrm{D}}$ ) rather than to the total boron concentration [B]. Note that this observation was made possible in Si co-doped with $\mathrm{B}$ and $\mathrm{P}$ because $p_{0}$ is, in such material, systematically below [B] whereas it is almost equal to $[\mathrm{B}]$ in uncompensated $\mathrm{B}$-doped $\mathrm{Si}$. This finding was initially explained by the existence of B-P pairs in compensated $\mathrm{Si}$ resulting in a decrease of available $\mathrm{B}_{\mathrm{s}}$ atoms for $\mathrm{B}_{\mathrm{s}} \mathrm{O}_{2 \mathrm{i}}$ complex formation. ${ }^{3}$ However, the existence of such B-P pairs in large proportion was later shown to be very doubt$\mathrm{ful}^{5,6}$ and thus unable to explain the observed reduction of $N_{\mathrm{t}, \mathrm{sat}} *$ in compensated $p$-type $\mathrm{Si}$.

In the light of those observations, Voronkov and Falster ${ }^{7}$ proposed a model consisting of a latent defect made of one interstitial boron atom $\mathrm{B}_{\mathrm{i}}$ and one oxygen dimer $\mathrm{O}_{2 \mathrm{i}}$. The linear dependence of $N_{\mathrm{t}, \mathrm{sat}}{ }^{*}$ on $p_{0}$ is thereby explained by the proportionality of the solubility $N_{\mathrm{Bi}}$ of positively charged $\mathrm{B}_{\mathrm{i}}{ }^{+}$in $p$-type $\mathrm{Si}$ to the free hole density, during the last stage

\footnotetext{
${ }^{\text {a) }}$ Author to whom correspondence should be addressed. Electronic mail: forster@apollonsolar.com.
}

of crystal cooling. The degradation is proposed to result from a change of the configuration of the defect triggered by the injection of excess carriers.

On the other hand, it is well-known that light-induced minority-carrier lifetime degradation does not take place in electronic-grade (EG)-Si doped with only gallium (Ga). This implies that either no complex can form between $\mathrm{Ga}$ atoms and $\mathrm{O}_{2 \mathrm{i}}$ (Refs. 2 and 8) or such complex is electrically inactive. ${ }^{9}$ In $\mathrm{Ga}$ and $\mathrm{B}$ co-doped $\mathrm{Cz}-\mathrm{Si}$ samples of the same total doping $p_{0}=[\mathrm{B}]+[\mathrm{Ga}] \approx 1.5 \times 10^{16} \mathrm{~cm}^{-3}$, Arivanandhan et al. ${ }^{10}$ measured lower lifetime after degradation in samples containing higher [B]. This result might lead one to question Voronkov and Falster's model which would expect, in Si containing $\mathrm{B}$, the amplitude of the degradation to be proportional to $p_{0}$ and independent on [B]. Arivanandhan's study was, however, based on minority-carrier lifetime measurements on samples with no surface passivation and in which $\left[\mathrm{O}_{\mathrm{i}}\right]$ was not measured, assuming the latter to be the same in all samples. Given the quadratic dependence of $N_{\mathrm{t}, \mathrm{sat}}$ * on [O $\mathrm{O}$ ] , an experimental measurement of $\left[\mathrm{O}_{\mathrm{i}}\right]$ is, however, essential. Moreover, the degraded lifetime was measured after only $120 \mathrm{~min}$ light-soaking which is a priori insufficient to ensure complete degradation.

In this work, we focus on the boron-oxygen (BO) defect in $\mathrm{Si}$ co-doped with $\mathrm{Ga}$ and $\mathrm{B}$ in which $p_{0}>[\mathrm{B}]$. We determine the saturated defect density and formation rate and study their dependences on $[\mathrm{B}]$ and $p_{0}$. The aim of the present work is to check whether the presence of $\mathrm{Ga}$ in $\mathrm{Si}$ codoped with B impacts on the formation of the BO defect and to verify if experimental results are consistent with a recently proposed defect model ${ }^{7}$ based on measurements in B-doped and $\mathrm{B}$ and $\mathrm{P}$ co-doped Si.

For that purpose, samples were selected at different heights $(20 \%, 30 \%$, and $40 \%)$ of a Cz-Si crystal of $50-70 \mathrm{~mm}$ in diameter, grown from a melt doped with $1.47 \times 10^{15} \mathrm{~cm}^{-3}$ of $\mathrm{B}$ and $1.67 \times 10^{18} \mathrm{~cm}^{-3}$ of $\mathrm{Ga}$. These samples, together with B-doped and Ga-doped Cz-Si control samples, were first subjected to a phosphorus-diffusion gettering at $820^{\circ} \mathrm{C}$ to dissolve oxygen-related thermal donors (TDs) and eliminate metallic impurities. This ensures that there is no or very little 
impact of $\mathrm{Fe}-\mathrm{B}$ or $\mathrm{Fe}-\mathrm{Ga}$ pairs during the degradation experiment. Then, samples were subsequently acid etched to remove the diffused layers and the saw damage, RCA cleaned and coated on both sides at low temperature $\left(400^{\circ} \mathrm{C}\right)$ with PECVD hydrogenated silicon-nitride $\left(\mathrm{SiN}_{\mathrm{x}}: \mathrm{H}\right)$ layers in order to ensure a good surface passivation. ${ }^{11}$ The samples' thicknesses, after acid etch, were in the range $130-560 \mu \mathrm{m}$. The minority-carrier lifetime $\tau(t)$ was then measured using the quasi-steady-state photoconductance (QSSPC) technique (Ref. 12) immediately after annihilation of the boron-oxygen defect by a $30 \mathrm{~min}$ annealing at $200^{\circ} \mathrm{C}$ in the dark $(t=0)$, and after different degradation times $t$ under a $10 \mathrm{~mW} / \mathrm{cm}^{2}$ light-soaking at a temperature of $25-27^{\circ} \mathrm{C}$. Samples were carefully protected from light-exposure between annealing and the initial minoritycarrier lifetime measurement to ensure that no BO defects were generated before the measurement of $\tau(0)$. The minoritycarrier lifetime degraded under illumination in all the samples except for the Ga-doped $\mathrm{Si}$ one, in which it remained stable (Fig. 1). This proves that the surface passivation quality of the $\mathrm{SiN}_{\mathrm{x}}: \mathrm{H}$ layer did not change throughout the experiment. The observed degradation in samples containing B can thus be attributed to a decrease of the bulk lifetime.

$\mathrm{SiN}_{\mathrm{x}}: \mathrm{H}$ layers were then etched off in hydrofluoric acid and $\left[\mathrm{O}_{\mathrm{i}}\right]$ was determined by Fourier transform infrared spectroscopy $\left(\right.$ FTIR) to be in the range $\left[\mathrm{O}_{\mathrm{i}}\right]=(6 \pm 1) \times 10^{17} \mathrm{~cm}^{-3}$ to $(11 \pm 2) \times 10^{17} \mathrm{~cm}^{-3}$. Carbon is also known to affect the defect density, ${ }^{2}$ presumably by capturing $\mathrm{O}_{2 \mathrm{i}} \cdot{ }^{13}$ Its concentration was measured in our samples by FTIR to be comprised in the narrow range $[C]=(7 \pm 1) \times 10^{16} \mathrm{~cm}^{-3}$ to $(9 \pm 2)$ $\times 10^{16} \mathrm{~cm}^{-3}$ and should thus not have a significant influence in the present study. In each sample, the carrier density $p_{0}$ is deduced from the resistivity measured with a four-point probe, in the range $0.7-10.4 \Omega . \mathrm{cm}$. In samples doped with B only, [B] is taken as equal to $p_{0}$, assuming complete dopant ionization. This assumption is valid since only samples with [B] lower than $2 \times 10^{16} \mathrm{~cm}^{-3}$ are considered in this work. ${ }^{14} \mathrm{In}$ samples co-doped with $\mathrm{Ga}$ and $\mathrm{B},[\mathrm{B}]$ is calculated from the sample's position in the crystal and the initial concentrations in the Si melt using the Scheil equation. In our samples, it lies in the range $[\mathrm{B}]=(1.2 \pm 0.5) \times 10^{15} \mathrm{~cm}^{-3}$ to $(1.3 \pm 0.9)$ $\times 10^{15} \mathrm{~cm}^{-3}$. Note that the high segregation coefficient of B in $\mathrm{Si}\left(k_{\mathrm{B}}=0.8\right)$ means that its concentration varies along the ingot much less than the concentration of Ga. In addition, no significant evaporation of $\mathrm{B}$ from the melt is expected to occur. Hence, the B concentration at a given height of the ingot can be determined with an accuracy that is sufficient for the purposes of the present study. These co-doped samples present the advantage for this study that they contain more $\mathrm{Ga}$ than $\mathrm{B}$ and therefore $p_{0}$ is about 10 times higher than [B]. This will enable us to clearly establish if the defect density's linear dependence on $p_{0}$, observed in compensated $\mathrm{Si}$ in which $p_{0}<[\mathrm{B}]$, is still valid when $p_{0}>[\mathrm{B}]$.

After a degradation time $t$, the effective defect density $N_{\mathrm{t}}^{*}(t)$ is calculated with the following expression,

$$
N_{\mathrm{t}}^{*}(t)=\frac{1}{\tau_{\mathrm{LID}}}=\frac{1}{\tau(t)}-\frac{1}{\tau(0)}
$$

$\tau(t)$ being the minority-carrier lifetime measured at a fixed excess-carrier injection $\Delta n$ equal to $10 \%$ of the carrier den-

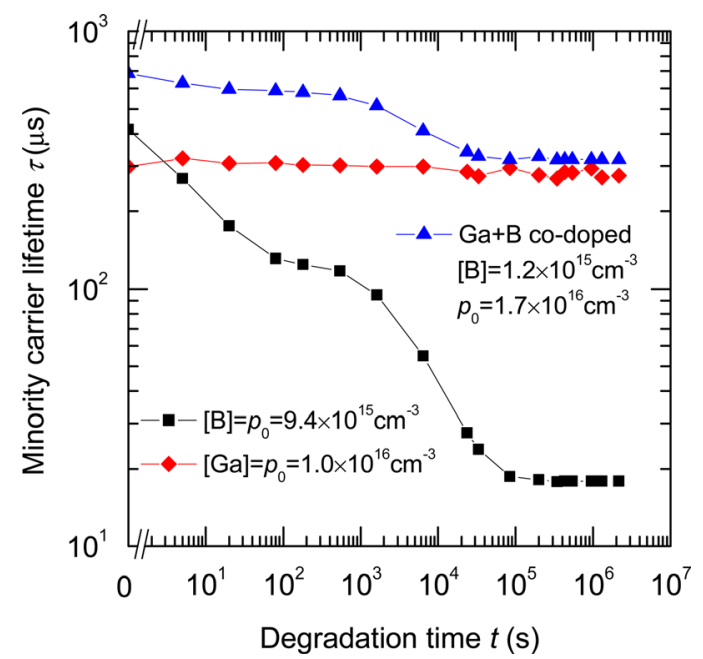

FIG. 1. (Color online) Minority-carrier lifetime measured in B-doped and Ga-doped controls and in Si co-doped with $\mathrm{Ga}$ and $\mathrm{B}$ as a function of time under illumination at $10 \mathrm{~mW} / \mathrm{cm}^{2}$. Lines are guides to the eye.

sity $p_{0}$ after illumination for a duration $t$. The evolution of $N_{\mathrm{t}}^{*}(t)$ with illumination time can be fitted, as previously reported, ${ }^{3}$ with

$$
N_{\mathrm{t}}^{*}(t)=N_{\text {fast }}^{*}+N_{\mathrm{t}, \mathrm{sat}}^{*} \cdot\left(1-\exp \left(-R_{\text {gen }} \cdot t\right)\right),
$$

in which $N_{\text {fast }}{ }^{*}$ accounts for a fast initial degradation occurring during the first few seconds of light exposure which can be observed in Fig. 1. Since this fast degradation has a very small impact on the final degraded $\tau$, we only focus on the slow-forming defect by studying its saturated effective density $N_{\mathrm{t}, \mathrm{sat}} *$ and formation rate constant $R_{\mathrm{gen}}$.

It is well known that $N_{\mathrm{t}, \text { sat }} *$ displays a quadratic dependence on $\left[\mathrm{O}_{\mathrm{i}}\right]$. This dependence is thought to be due to the participation of oxygen dimers ${ }^{2}$ which are themselves present in a concentration proportional to $\left[\mathrm{O}_{\mathrm{i}}\right]$ squared. ${ }^{13}$ Hence, small variations in $\left[\mathrm{O}_{\mathrm{i}}\right]$ from sample to sample can lead to significant variations in $N_{\mathrm{t}, \mathrm{sat}}$ * even for equal doping levels. Since we intend to study the impact of dopant concentration on the defect density and the nature of the B atom involved in the complex, a more relevant parameter to focus on is $N_{\mathrm{BC}}=N_{\mathrm{t}, \mathrm{sat}} * /\left[\mathrm{O}_{\mathrm{i}}\right] .^{2} \quad$ This oxygen-normalized parameter reflects the influence of defect components (such as [B] or $p_{0}$ ) not directly related to $\left[\mathrm{O}_{\mathrm{i}}\right]$.

The relative defect density $N_{\mathrm{BC}}$ measured for three samples co-doped with Ga and B and three B-doped control samples is plotted in Fig. 2 as a function of $p_{0}$ and [B]. For comparison, we have also plotted a linear regression of experimental data points from Schmidt and Bothe ${ }^{2}$ obtained on uncompensated $\mathrm{B}$-doped $\mathrm{Cz}-\mathrm{Si}$ samples. A reduction of the BO defect density by about a factor of 2 was found by the same authors in P-diffused $\mathrm{Si}$ as compared to as-cut $\mathrm{Si}^{15}$ Since our samples underwent a phosphorus-diffusion, whereas the samples from Ref. 2 did not, we have corrected the linear fit from Ref. 2 by dividing the effective defect density by 2 , in order to be able to compare it with our measurements. We have also plotted for comparison two points from Lim et $a l^{4}$ on P-diffused B and P compensated $p$-type Si. These two points correspond to the seed and tail ends of the ingot studied in their paper, for which the measured value of 


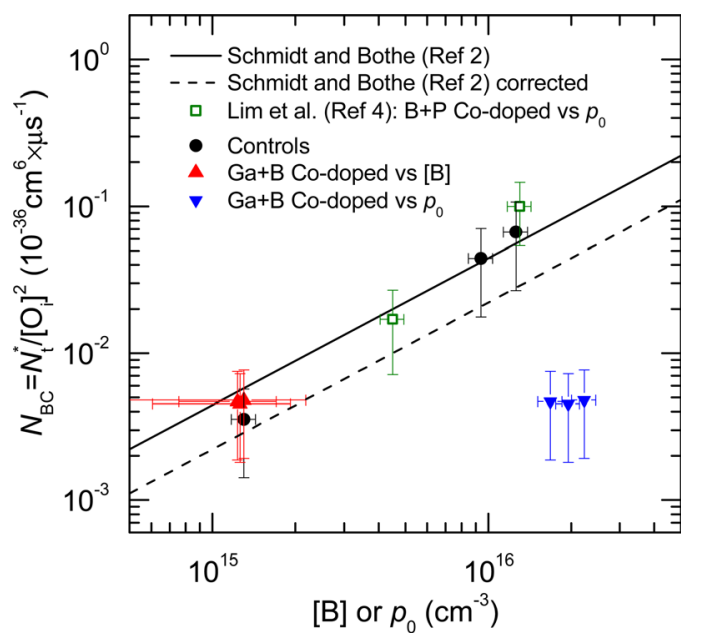

FIG. 2. (Color online) Relative saturated defect density plotted in B-doped controls and in Si co-doped with B and Ga as a function of the B concentration or the carrier density. Solid line is a fit to experimental data on B-doped Si from Ref. 2. Dashed line corresponds to the same fit divided by a correction factor of 2 to account for the defect density reduction expected in P-diffused Si. Open symbols correspond to effective defect density from Ref. 4 measured in P-diffused B and P compensated $\mathrm{Si}$ and plotted as a function of $p_{0}$.

$\left[\mathrm{O}_{\mathrm{i}}\right]$ was reported. As can be seen in Fig. 2, B-doped controls measured in the present work agree well with the previously measured defect density, which supports the validity of our experimental setup. In samples co-doped with $\mathrm{Ga}$ and $\mathrm{B}$, however, $N_{\mathrm{BC}}$ is reduced by more than one order of magnitude compared to B-doped $\mathrm{Si}$ when plotted against $p_{0}$. On the other hand, it scales well with B-doped Si when plotted as a function of [B]. Note that the drastic reduction of $N_{\mathrm{BC}}$ compared to the linear dependence on $p_{0}$ is only observable in these samples because [B] is about 10 times lower than $p_{0}$ due to the high concentration of $\mathrm{Ga}$. We conclude from this result that in Si co-doped with $\mathrm{B}$ and $\mathrm{Ga}$, the defect density is not related to $p_{0}$ but is, instead, proportional to [B]. This gives a general picture of the defect in which its density is proportional to $p_{0}=N_{\mathrm{A}}-N_{\mathrm{D}}$ when $p_{0}<[\mathrm{B}]$ (i.e., when codoped with P (Refs. 3 and 4)) and to [B] when $p_{0}>$ [B] (i.e., when co-doped with Ga). Voronkov and Falster's model ${ }^{7}$ fails to describe the present result, since the concentration of dissolved interstitial $B_{i}$ involved in that defect model is believed to be proportional to $p_{0}$ and independent on [B]. Instead, the proportionality with $[\mathrm{B}]$, found in our experiments, indicates the participation of substitutional $B_{s}$ in the defect formation. The reduction of the defect density observed in $\mathrm{Si}$ compensated with $\mathrm{P}$ as compared to the expected linear dependence on $[\mathrm{B}]$ remains, however, to be explained.

One could also imagine that the defect is made of $\mathrm{B}_{\mathrm{i}}$, according to Voronkov and Falster's model, but that either one of the two densities of $\mathrm{B}_{\mathrm{i}}$ or $\mathrm{O}_{2 \mathrm{i}}$ is strongly affected by the presence of $\mathrm{Ga}$. For example, the formation of $\mathrm{B}_{\mathrm{i}} \mathrm{Ga}_{\mathrm{s}}$ or $\mathrm{Ga}_{\mathrm{s}} \mathrm{O}_{2 \mathrm{i}}$ pairs during the cooling of samples after phosphorus-diffusion is conceivable. No indication of the existence of such complexes has, however, been reported yet. Further investigation would be necessary to assess if they would be stable enough to reduce either concentrations of $\mathrm{B}_{\mathrm{i}}$ or $\mathrm{O}_{2 \mathrm{i}}$ to such an extent that the $\mathrm{BO}$ defect density would decrease by more than one order of magnitude, as it is observed in this work.

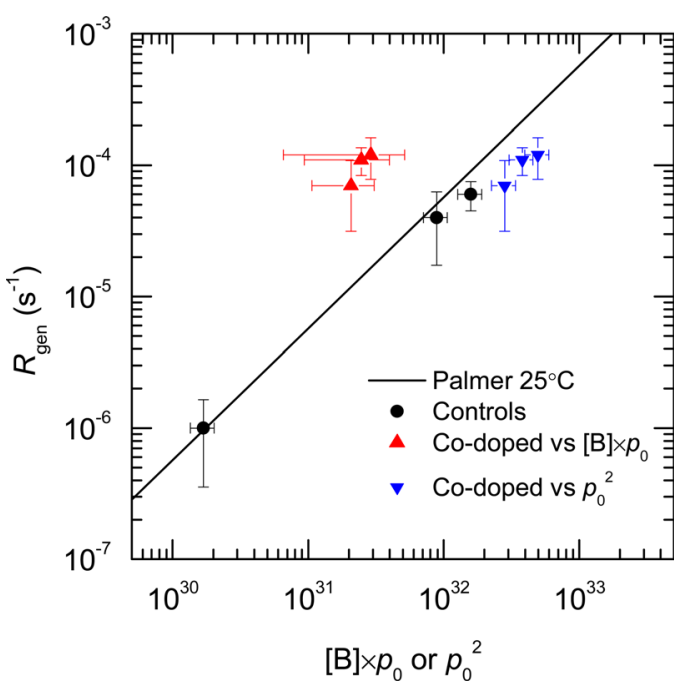

FIG. 3. (Color online) Defect formation rate constant plotted as a function of $p_{0}{ }^{2}$ or [B] $\times p_{0}$, in B-doped controls and Si co-doped with B and Ga. Solid line represents $R_{\text {gen }}$ at $25^{\circ} \mathrm{C}$ as calculated with Palmer's model.

The formation rate constant $R_{\text {gen }}$ of the slow forming BO defect can also be informative to understand the genesis of the defect. Its value, extracted from the fit of equation (2) to the measured $N_{\mathrm{t}}{ }^{*}(t)$, is plotted in Fig. 3 against $p_{0}{ }^{2}$ and $p_{0} \times$ [B]. Fig. 3 also depicts $R_{\text {gen }}$ calculated with Palmer's model, which fits previous experimental data in uncompensated B-doped $\mathrm{Si}^{16}$ As can be seen, $R_{\text {gen }}$ measured in the $\mathrm{B}$ doped controls agrees well with Palmer's model, which again proves the validity of our experimental setup.

Depending on the defect formation mechanism, the formation rate constant $R_{\text {gen }}$ is believed to depend either on $p_{0}{ }^{2}$ or on $p_{0} \times[\mathrm{B}]$. A linear dependence on $p_{0}^{2}$ is expected from the reconstruction of a latent defect, ${ }^{7}$ whereas a defect reaction involving the diffusion of mobile $\mathrm{O}_{2 \mathrm{i}}$ under illumination should result in our samples in a linear dependence on $p_{0} \times[\mathrm{B}],{ }^{16}$ since the B-related component of the defect was shown to be proportional to [B]. In the co-doped samples measured in this work, $R_{\text {gen }}$ scales well with uncompensated Si when plotted against $p_{0}^{2}$ but shows significant deviation when plotted against $p_{0} \times[\mathrm{B}]$. It is worth noting that in $p$-type $\mathrm{Si}$ co-doped with $\mathrm{B}$ and $\mathrm{P}, R_{\text {gen }}$ is also proportional to $p_{0}{ }^{2}$, despite the fact that $p_{0}<[\mathrm{B}] .^{3,4}$ It seems, therefore, that whatever the ratio between $p_{0}$ and [B], $R_{\text {gen }}$ is always determined by $p_{0}{ }^{2}$ and independent on [B]. This result therefore supports the version of the defect model in which it is activated by the reconfiguration of its latent state into a recombination-active form. Note that this does not contradict our previous conclusion that $\mathrm{B}_{\mathrm{s}}$ is involved in the defect complex instead of $B_{i}$. The latent character of the complex does not imply a specific composition; the existence of a latent $\mathrm{B}_{\mathrm{s}} \mathrm{O}_{2 \mathrm{i}}$ defect that would form during $\mathrm{Si}$ cooling is possible.

In summary, we have measured the effective BO defect density in Si co-doped with $\mathrm{B}$ and $\mathrm{Ga}$ to be significantly reduced compared to the linear dependence on $p_{0}$ expected by the model recently proposed by Voronkov and Falster. ${ }^{7}$ Instead, the defect density in samples studied in this work shows a good agreement with a linear dependence on [B]. This result could be explained either by the involvement of 
$B_{s}$ instead of $B_{i}$ in the defect or by the reduction of the density of $\mathrm{B}_{\mathrm{i}}$ or $\mathrm{O}_{2 \mathrm{i}}$ due to the presence of $\mathrm{Ga}$. In any case, the implications of this result for solar cells are positive. For example, it shows that the addition of Ga during crystallization of UMG-Si, used to control the Si doping uniformity, ${ }^{17}$ does not lead, as would be expected by Voronkov and Falster's model, to a stronger degradation. Finally, the measured linear dependence of $R_{\text {gen }}$ on $p_{0}^{2}$ supports a model for the defect formation based on the activation of a latent defect, rather than due to the diffusion and trapping of $\mathrm{O}_{2 \mathrm{i}}$.

${ }^{1}$ J. Kraiem, B. Drevet, F. Cocco, N. Enjalbert, S. Dubois, D. Camel, D. Grosset-Bourbange, D. Pelletier, T. Margaria, and R. Einhaus, in Proceedings 35th IEEE Photovoltaic Specialists Conference, Hawaii (IEEE, New York, 2010).

${ }^{2}$ J. Schmidt and K. Bothe, Phys. Rev. B 69, 024107 (2004).

${ }^{3}$ D. Macdonald, F. Rougieux, A. Cuevas, B. Lim, J. Schmidt, M. D. Sabatino, and L. J. Geerligs, J. Appl. Phys. 105, 093704 (2009).

${ }^{4}$ B. Lim, F. Rougieux, D. Macdonald, K. Bothe, and J. Schmidt, J. Appl. Phys. 108, 103722 (2010).
${ }^{5}$ D. Macdonald, A. Liu, F. Rougieux, A. Cuevas, B. Lim, J. Schmidt., M. D. Sabatino, and L. J. Geerligs, in Proceedings of the 24th European Photovoltaic Solar Energy Conference, Hamburg, Germany (WIP, Munich, 2009), p. 877.

${ }^{6}$ T. Schutz-Kuchly, J. Veirman, S. Dubois, and D. R. Heslinga, Appl. Phys. Lett. 96, 093505 (2010).

${ }^{7}$ V. V. Voronkov and R. Falster, J. Appl. Phys. 107, 053509 (2010).

${ }^{8}$ M. Sanati and S. K. Estreicher, Physica B 376-377, 133 (2006).

${ }^{9}$ J. Adey, R. Jones, D. W. Palmer, P. R. Briddon, and S. Öberg, Phys. Rev. Lett. 93, 055504 (2004).

${ }^{10}$ M. Arivanandhan, R. Gotoh, K. Fujiwara, and S. Uda, J. Appl. Phys. 106, 013721 (2009).

${ }^{11}$ J.-F. Lelièvre, E. Fourmond, A. Kaminski, O. Palais, D. Ballutaud, and M. Lemiti, Sol. Energy Mater. Solar Cells 93, 1281 (2009).

${ }^{12}$ R. A. Sinton and A. Cuevas, Appl. Phys. Lett. 69, 2510 (1996).

${ }^{13}$ L. I. Murin, T. Hallberg, V. P. Markevich, and J. L. Lindström, Phys. Rev. Lett. 80, 93 (1998).

${ }^{14}$ P. P. Altermatt, A. Schenk, B. Schmithusen, and G. Heiser, J. Appl. Phys. 100, 113715 (2006).

${ }^{15}$ K. Bothe, R. Sinton, and J. Schmidt, Prog. Photovoltaics 13, 287 (2005).

${ }^{16}$ D. W. Palmer, K. Bothe, and J. Schmidt, Phys. Rev. B 76, 035210 (2007).

${ }^{17}$ M. Forster, E. Fourmond, R. Einhaus, H. Lauvray, J. Kraiem, and M. Lemiti, Phys. Status Solidi C 8, 678 (2011). 